\title{
The effect of bed-to-nurse ratio on hospital mortality of critically ill children on mechanical ventilation: a nationwide population-based study
}

Minyoung Jung ${ }^{1 \dagger}$, Hyejeong Park ${ }^{2,3 \dagger}$, Danbee Kang ${ }^{3,4}$, Esther Park ${ }^{2}$, Kyeongman Jeon $^{2}$, Chi Ryang Chung ${ }^{2}$, Jeong Hoon Yang ${ }^{2}$, Gee Young Suh ${ }^{2,3}$, Eliseo Guallar ${ }^{3,5}$, Juhee $\mathrm{Cho}^{3,4}$ and Joongbum Cho ${ }^{2^{*}}$ (1)

\begin{abstract}
Background: Despite the high workload of mechanical ventilation, there has been a lack of studies on the association between nurse workforce and mortality in mechanically ventilated patients. We evaluated the association of the bed-to-nurse ratio with mortality in ventilated pediatric patients admitted to an intensive care unit (ICU).

Methods: We conducted a nationwide retrospective analysis by using the Korean National Health Insurance database, which categorizes the bed-to-nurse ratio into 9 grades according to the number of beds divided by the number of full-time equivalent registered nurses in a unit. Patients of ages between 28 days and 18 years were enrolled. Multiple admissions and transfers from other hospitals were excluded. We evaluated the odds ratios (ORs) of in-hospital mortality using 4 groups (Grade 1: bed-to-nurse $<0.50$, Grade 2: $<0.63$, Grade 3: $<0.77$, Grade 4 or above $>0.77$ ) with adjustment of patient factors, hospital factors, and treatment requirements.
\end{abstract}

Results: Of the 27,849 patients admitted to ICU, 11,628 (41.8\%) were on mechanical ventilation. The overall in-hospital mortality rates in Grade 1, Grade 2, Grade 3, and Grade 4 or above group were 4.5\%, 6.8\%, 6.9\%, and 4.7\%, respectively. The adjusted ORs (95\% Cl) for in-hospital mortality of mechanically ventilated patients in the Grade 2, Grade 3 , and Grade 4 or above compared to those in Grade 1 were 2.73 (95\% Cl 1.51-4.95), 4.02 (95\% Cl 2.23-7.26), and 7.83 (4.07-15.07), respectively. However, for patients without mechanical ventilation, the adjusted ORs of in-hospital mortality were not statistically significant.

Conclusion: In mechanically ventilated patients, the adjusted mortality rate increased significantly, as the bed-tonurse ratio of the ICU increased. Policies that limit the number of ventilated patients per nurse should be considered. Trial registration retrospectively registered

Keywords: Mechanical ventilation, Nurse staffing, Critical care, Critical care outcomes, Pediatric intensive care units, Quality of care, Mortality, Epidemiology, National Health Insurance

*Correspondence: joongbum.cho@gmail.com; Joongbum.cho@samsung. com

${ }^{\dagger}$ Minyoung Jung and Hyejeong Park contributed equally to this work as co-first authors

2 Department of Critical Care Medicine, Samsung Medical Center, Sungkyunkwan University School of Medicine, 81 Irwon-ro, Gangnam-gu, Seoul 06351, Republic of Korea

Full list of author information is available at the end of the article

\section{Background}

The nurse staffing ratio is associated with the quality of care and safety of a hospital [1-4]. In an intensive care unit (ICU), unplanned extubation, central line-associated bloodstream infection, and ventilator-associated pneumonia are associated with a small number of nurses, although the bed-to-nurse ratio is smaller in the ICU

\section{Springer Open}

(c) The Author(s) 2020. This article is licensed under a Creative Commons Attribution 4.0 International License, which permits use, sharing, adaptation, distribution and reproduction in any medium or format, as long as you give appropriate credit to the original author(s) and the source, provide a link to the Creative Commons licence, and indicate if changes were made. The images or other third party material in this article are included in the article's Creative Commons licence, unless indicated otherwise in a credit line to the material. If material is not included in the article's Creative Commons licence and your intended use is not permitted by statutory regulation or exceeds the permitted use, you will need to obtain permission directly from the copyright holder. To view a copy of this licence, visit http://creativeco mmons.org/licenses/by/4.0/. 
than in the general ward [5-7]. Organizations of critical care nursing professionals suggested minimum standards on nurse staffing ratios $[8,9]$. The standards specified that the number of patients assigned to one nurse should be smaller in mechanically ventilated patients than in other patients in an ICU.

Mechanical ventilation is a cause of high nursing workload in ICU [10, 11]. A high workload is associated with patient mortality [12]. However, there are highlevel ICUs, even in a developed country, which do not meet the suggested standards [13]. The global shortage of registered nurses might compromise the compliance of nursing standards [14]. In addition, there is a lack of studies on the association between mortality and nurse staffing ratio in ventilated patients [15]. Results of studies on the association between nurse staffing ratio and mortality were inconsistent $[16,17]$.

Therefore, we evaluated the association between bedto-nurse ratio and mortality rate according to the use of mechanical ventilation in pediatric patients in an ICU using a national database.

\section{Methods \\ Study population}

We conducted a retrospective cohort analysis of the Health Insurance Review and Assessment (HIRA) database from the Korean Ministry of Health [18, 19]. Korean National Health Insurance Service (NHIS) and Medical Aid Program (MAP) cover all Korean citizens by law. All hospitals have to claim for reimbursement of ICU treatment to Korean NHIS and MAP, and HIRA reviews the claims for payment. HIRA database included nearly all ICU admissions in Korea except administrative mistakes.

The ICU admissions were defined using the claim codes, which are mandatory for ICU management of inhospital stays (codes AJ100-AJ590900) in all Korean hospitals. All ICU stays during the same hospitalization were considered as a single ICU admission. Hospital stays separated by $<2$ days were considered as the same hospital admission.

The study population consisted of all patients $<18$ years of age with at least one ICU admission (regardless of ICU types) covered by the Korean National Health System between August 30, 2009, and September 30, 2014 ( $n=130,721$ infants, children or adolescents). We excluded patients with multiple admissions during the study period $(n=63,156)$ to exclude the effect of multiple admission and transfer on the mortality rate. Since we aimed to evaluate the effects of hospitals according to nurse staffing ratio, we additionally excluded participants who were transferred within one day after discharge $(n=2,100)$. We also excluded patients who were neonates ( $<28$ days), admitted to an NICU (codes AJ101,
AJ111, AJ121, AJ141, AJ201, AJ211, AJ221, AJ241, AJ301, AJ311, AJ321, and AJ341; $n=37,475)$ since NICU has different bed-to-nurse grade system. On the other hand, we included all children in adult ICU, since adult ICU shares the same bed-to-nurse grade system. We excluded patients admitted with a primary diagnosis code of Z00Z99 (factors influencing health status and contact with health services; $n=141$ ). The final sample was 27,849 patients (Additional file 1: Fig. S1).

The sampling procedures and representativeness of the pediatric ICU cohort have been described elsewhere [19]. Our study was reviewed by the Institutional Review Board (IRB) of Samsung Medical Center (IRB protocol 2015-11-17), and informed consent was exempted because of the use of previously collected de-identified administrative data.

\section{Measurement}

We categorized bed-to-nurse grades according to the Korean National Health Insurance (NHI) codes of ICU admission (AJ11-AJ19, AJ21-AJ29, AJ31-AJ39). These codes were designed to reimburse hospitals for ICU care service costs according to the bed-to-nurse ratio. The Korean NHI defined the bed-to-nurse ratio as the number of beds divided by the number of full-time equivalent registered nurses in a unit. There were 9 categories of codes: Grade 1 (bed-to-nurse $<0.50$, the best), Grade 2 (bed-to-nurse $<0.63$ ), Grade 3 (bed-to-nurse $<0.77$ ), Grade 4 (bed-to-nurse $<0.88$ ), Grade 5 (bed-tonurse $<1.00$ ), Grade 6 (bed-to-nurse $<1.25$ ), Grade 7 (bed-to-nurse $<1.50$ ), Grade 8 (bed-to-nurse $<2.0$ ), and Grade 9 (bed-to-nurse $\geq 2.0$, the worst). When we convert the bed-to-nurse ratio to the estimated number of patients cared for by an acting nurse at a particular time, less than 2.1 patients were cared for by a nurse in Grade $1 \mathrm{ICU},<2.7$ patients in Grade $2 \mathrm{ICU},<3.3$ patients in Grade $3 \mathrm{ICU}$, and $<3.7$ patients in Grade $4 \mathrm{ICU}$ using the assumption of $2040 \mathrm{~h}$ of annual work per nurse [20, 21]. In this study, we grouped Grade 4 or above in one, because few patients were admitted to ICUs above Grade 4 , and they were not appropriate for ICU categorization.

Information on interventions, demographics, and hospital characteristics was based on claim codes. Primary diagnosis was defined as the condition primarily responsible for the patient's need for treatment or investigation using Korean Classification of Disease, sixth edition, which is the modified version of the International Classification of Disease, 10th revision adapted for use in the Korean health system [22]. Interventions for critical care included the use of mechanical ventilation for more than $3 \mathrm{~h}$ (Korean NHI procedure codes M5857, M5858, and M5860), extracorporeal membrane oxygenation (O1901-O1904), continuous renal replacement 
therapy (O7051-O7054), intermittent hemodialysis (HD; O7020), peritoneal dialysis (PD; O7062), and cardiopulmonary resuscitation (M5871, M5873, M5874, M5875, M5876, and M5877). We identified the use of vasopressor drugs such as dobutamine [Anatomic Therapeutic Chemical (ATC) codes: C01CA07], dopamine (ATC codes: C01CA04), epinephrine (ATC codes: C01CA24), and norepinephrine (ATC codes: C01CA03) for more than 2 days using Korean drug and anatomical therapeutic chemical codes [23]. We obtained information on hospital characteristics from the HIRA Medical Care Institution Database, which included information regarding type of institution, location, number of beds, facilities, and physicians. Hospitals were classified according to capacity based on number of hospital beds and number of specialties as defined by the Korean Health Law, as described in a previous study [19]. In addition, we included ICU admission volume as a hospital factor by calculating the average annual pediatric admissions to the ICU for 5 years in each hospital.

\section{Statistical analysis}

We conducted a descriptive analysis of patient characteristics across ICU groups. Mean with standard deviation or median with interquartile range were used to describe the distribution of continuous variables. Chi-square and Student's $t$-tests were used to compare categorical and continuous variables, respectively.

The outcome of the study was all-cause mortality. We calculated ORs with 95\% confidence interval (CI) for inhospital mortality using logistic regression. We used two models with increasing degrees of adjustment to account for potential confounding factors. Model 1 was adjusted for age, sex, and primary diagnosis as patient factors. Model 2 was adjusted for hospital factors and interventions in addition to patient factors. Since ICU admission volume and region had multicollinearity, we excluded the variables from the model.

In addition, we explored the association of bed-tonurse ratio with in-hospital mortality in pre-specified clinically relevant subgroups defined by the use of mechanical ventilation (yes vs. no), type of hospital (tertiary vs. general or hospital), and admission department (medical vs. surgical).

All analyses were performed using SAS enterprise guide 6.1 (SAS Institute, Cary, NC, USA). Twosided significance testing was used throughout, with a $p$-value $<0.05$ considered statistically significant.

\section{Results}

Between August 2009 and September 2014, a total of 27,849 patients were admitted to an ICU. The median (interquartile range) age was $6(1-14)$ years, and 58.0\% were male (Table 1$)$. The most frequent primary diagnosis was congenital anomaly (28.6\%); injury $(17.3 \%)$ and neoplasms $(11.3 \%)$ were the next common. Mechanical ventilation was applied to $41.8 \%$ of patients, and $20.3 \%$ of patients required vasopressors.

Among patients, 11,691 (42.0\%) were in Grade 1, 5095 (18.3\%) in Grade 2, 6797 (24.4\%) in Grade 3, and $4266(15.3 \%)$ in Grade 4 or above group. Compared with patients in ICU Grade 4 or above, patients in ICU Grade 1 were more likely to be younger (median 4 vs. 13, $p<0.01)$ and to require mechanical ventilation $(56.5 \%$ vs. $12.1 \% ; p<0.01)$, vasopressor drugs $(23.1 \%$ vs. $7.4 \%$, $p<0.01)$, or hemodialysis $(4.3 \%$ vs. $0.9 \%, p<0.01)$. The most common primary diagnosis was injury (46.2\%) in Grade 4 or above and congenital anomalies (45\%) in Grade 1 (Table 1).

Among 27,849 patients, 1543 (5.5\%) died in hospital. The in-hospital mortality rates in Grade 1, Grade 2, Grade 3, and Grade 4 or above group were $4.5 \%, 6.8 \%$, $6.9 \%$, and $4.7 \%$, respectively (Fig. 1). The fully adjusted ORs (model 2) for in-hospital mortality for patients in ICU Grade 2, ICU Grade 3, and ICU Grade 4 or above compared with those in ICU Grade 1 were 2.49 (95\% CI 1.46-4.24), 3.61 (95\% CI 2.13-6.14), and 4.74 (2.65-8.46), respectively (Table 2 ). Among patients on mechanical ventilation $(n=11,682)$, the adjusted ORs $(95 \% \mathrm{CI})$ for in-hospital mortality of patients in Grade 2, Grade 3, Grade 4 or above compared to patients in Grade 1 were 2.73 (95\% CI 1.51-4.95), 4.02 (95\% CI 2.23-7.26), and 7.83 (4.07-15.07), respectively. However, for patients without mechanical ventilation, the adjusted ORs of inhospital mortality did not increase with statistical significance according to the increase of ICU grade.

In patients with mechanical ventilation, the positive association between bed-to-nurse ratio and in-hospital mortality was observed regardless of type of hospital and medical/surgical admission department (Fig. 2).

For patients to whom vasopressors were applied but not mechanical ventilation, there was no significant increase in the risk of in-hospital mortality as bed-tonurse ratios increased (Additional file 2: Table S1).

\section{Discussion}

Our study showed that the adjusted risk of mortality increased as the bed-to-nurse ratio increased in mechanically ventilated patients using population-based nationwide data. The association was consistent regardless of hospital type, or admission department. In the patients without mechanical ventilation, no association between adjusted risk of mortality and the bed-to-nurse ratio was shown. This nationwide study was conducted without bias caused by hospital selection and showed that ICU 
Table 1 Characteristics of patients admitted to ICU according to ICU grade in Korea, August 2009 to September 2014

\begin{tabular}{|c|c|c|c|c|c|}
\hline \multirow[t]{2}{*}{ Characteristics } & \multicolumn{4}{|c|}{ ICU bed-to-nurse grade ${ }^{b}$} & \multirow[t]{2}{*}{$p$-value } \\
\hline & $\begin{array}{l}\text { Grade } 1 \\
(n=11,691)\end{array}$ & $\begin{array}{l}\text { Grade } 2 \\
(n=5095)\end{array}$ & $\begin{array}{l}\text { Grade } 3 \\
(n=6797)\end{array}$ & $\begin{array}{l}\text { Grade } 4 \text { or above } \\
(n=4266)\end{array}$ & \\
\hline Age, years & $6.0(5.5)$ & $7.4(6.1)$ & $8.0(6.1)$ & $10.5(5.9)$ & $<0.01$ \\
\hline Age, year, median (IQR) & $4(0.9,11)$ & $6(0.9,14)$ & $7(1,14)$ & $13(5,16)$ & $<0.01$ \\
\hline Sex, male & $6323(54.1)$ & $3024(59.4)$ & $4143(61.0)$ & $2663(62.4)$ & $<0.01$ \\
\hline Type of hospital & & & & & $<0.01$ \\
\hline Tertiary hospital & $10,763(92.1)$ & $3342(65.6)$ & $4134(60.8)$ & $338(7.9)$ & \\
\hline General hospital & $928(7.9)$ & $1752(34.4)$ & $2650(39.0)$ & $3700(86.7)$ & \\
\hline Hospital & $0(0.0)$ & $1(0.0)$ & $13(0.2)$ & $228(5.3)$ & \\
\hline ICU admission volume ${ }^{\mathrm{a}}$ & & & & & $<0.01$ \\
\hline$>600$ per year & $2962(25.3)$ & $0(0.0)$ & $0(0.0)$ & $0(0.0)$ & \\
\hline 100-600 per year & $8228(70.4)$ & $1948(38.2)$ & $1520(22.4)$ & $28(0.7)$ & \\
\hline$<100$ per year & $501(4.3)$ & $3147(61.8)$ & $5277(77.6)$ & $4238(99.3)$ & \\
\hline Region & & & & & $<0.01$ \\
\hline Capital & 10,339 (88.4) & $1550(30.4)$ & $877(12.9)$ & $750(17.6)$ & \\
\hline Metropolitan & $10(0.1)$ & $1471(28.9)$ & $3270(48.1)$ & $596(14.0)$ & \\
\hline Province & $1342(11.5)$ & $2074(40.7)$ & $2650(39.0)$ & $2920(68.4)$ & \\
\hline Admission department & & & & & $<0.01$ \\
\hline Surgical & $7773(66.5)$ & $3011(59.1)$ & 3099 (45.6) & $2162(50.7)$ & \\
\hline Medical & 3918 (33.5) & $2084(40.9)$ & $3698(54.4)$ & $2104(49.3)$ & \\
\hline Primary diagnosis & & & & & $<0.01$ \\
\hline Congenital anomaly & $5268(45.1)$ & $1724(33.8)$ & $857(12.6)$ & $117(2.7)$ & \\
\hline Injury & $314(2.7)$ & $812(15.9)$ & $1730(25.5)$ & $1969(46.2)$ & \\
\hline Neoplasms & $2164(18.5)$ & $365(7.2)$ & $405(6.0)$ & $220(5.2)$ & \\
\hline Respiratory & $560(4.8)$ & $479(9.4)$ & $1186(17.4)$ & $642(15.0)$ & \\
\hline Neurologic disease & $1024(8.8)$ & $496(9.7)$ & $671(9.9)$ & $330(7.7)$ & \\
\hline Circulatory disease & $1107(9.5)$ & $399(7.8)$ & $517(7.6)$ & $156(3.7)$ & \\
\hline Gastrointestinal disease & $287(2.5)$ & $154(3.0)$ & $282(4.1)$ & $255(6.0)$ & \\
\hline Not elsewhere classified & $80(0.7)$ & $105(2.1)$ & $360(5.3)$ & $148(3.5)$ & \\
\hline Infectious disease & $131(1.1)$ & $130(2.6)$ & $237(3.5)$ & $97(2.3)$ & \\
\hline Others & $756(6.5)$ & $431(8.5)$ & $552(8.1)$ & $332(7.8)$ & \\
\hline \multicolumn{6}{|l|}{ Interventions for critical care } \\
\hline Mechanical ventilation & $6610(56.5)$ & $2582(50.7)$ & $1920(28.2)$ & $516(12.1)$ & $<0.01$ \\
\hline Vasopressors & $2696(23.1)$ & $1263(24.8)$ & $977(14.4)$ & $315(7.4)$ & $<0.01$ \\
\hline ECMO & $142(1.2)$ & $53(1.0)$ & $58(0.9)$ & $13(0.3)$ & $<0.01$ \\
\hline Hemodialysis & $504(4.3)$ & $110(2.2)$ & $105(1.5)$ & $40(0.9)$ & $<0.01$ \\
\hline CPR & $382(3.3)$ & $298(5.8)$ & 404 (5.9) & $161(3.8)$ & $<0.01$ \\
\hline
\end{tabular}

Values are median (interquartile range) or $n(\%)$

$I Q R$ interquartile range, ICU intensive care unit, ECMO extracorporeal membrane oxygenation, CPR cardiopulmonary resuscitation

a ICU admission volume was calculated as the average annual pediatric admissions to the ICU for 5 years in each hospital

b ICU bed-to-nurse grade was defined as bed-to-nurse ratio (Grade 1: $<0.5$, Grade 2: $<0.63$, Grade 3: $<0.77$, and Grade 4 or above: $>0.77$ )

admission volume was correlated with bed-to-nurse ratio (Additional file 3: Table S2).

There are several possible explanations for the sensitivity of hospital mortality of ventilated patients to bedto-nurse ratio. Mechanical ventilation requires high workload from the nurse [24, 25], including additional medications (sedatives, neuromuscular blockers), additional procedures (endotracheal intubation, tube maintenance, and chest physiotherapy), and equipment management (ventilator preparation, alarm response, and humidity control). Increased nurse workload is associated with ICU patient mortality $[12,26]$. Insufficient 


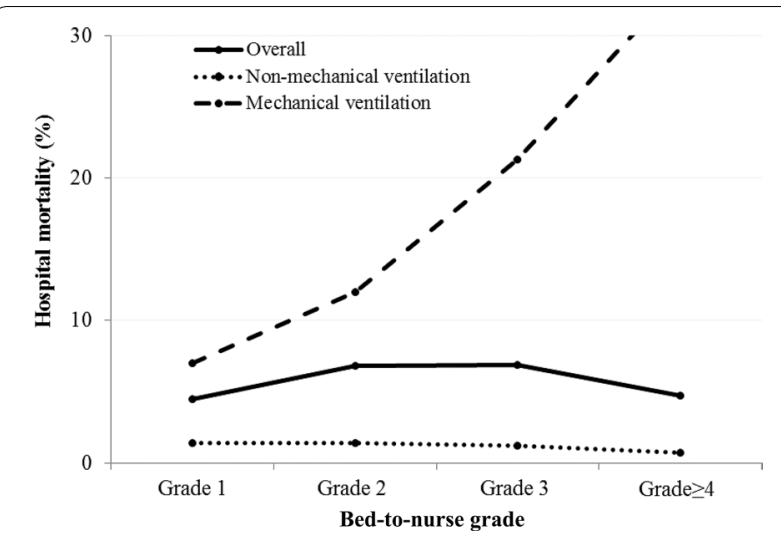

Fig. 1 Unadjusted hospital mortality according to ICU bed-to-nurse grade

physician collaboration, poor nurse-patient communication, increased medical errors, and nosocomial infection are possible causes of the association of high nurse workload and increased mortality [26-29]. Moreover, mechanical ventilation requires intensive monitoring of patients and equipment parameters. Failure of such monitoring may cause life-threatening complications such as pneumothorax or unexpected extubation, which requires prompt recognition and treatment $[5,30]$. Shortage of nursing staff could be associated with insufficient supervision and might inhibit early recognition of patients' changes [31].

For patients on mechanical ventilation, we only found one study about the association of nurse staffing ratio and mortality rate. The study reported no association between number of nurses and mortality in ventilated adult patients [15]. The different results from our study might come from the difference in age of patients or from the different nurse staffing ratios of studying ICUs. Pediatric patients have a short tracheal length, which is a risk for dislodgement, and their developmental immaturity commonly causes poor cooperation with ICU staff [32]. Therefore, more surveillance or workload may be required to care for ventilated children than cooperating adult patients. In the referred adult study, ICU nurses cared for about 2.15 (mean) patients each, and the patient number did not vary across hospitals (standard deviation: 0.37) [15]. However, in our study, the number of patients varied between less than 2.1 (Grade 1) to more than 3.7 (Grade 4 or above). Our study showed that risk of mortality increased in ICU patients as the number of patients increased above 2.1, but we could not evaluate the effect of 1 or less patient cared for by a nurse.

Table 2 Odds ratio $(95 \% \mathrm{CI})$ for in-hospital mortality according to ICU grade and use of mechanical ventilator in South Korea, 2009 to 2014

\begin{tabular}{|c|c|c|c|c|}
\hline Bed-to-nurse grade & No. of patients & No. of deaths (\%) & $\begin{array}{l}\text { Model } 1 \\
\text { OR }(95 \% \mathrm{Cl})\end{array}$ & $\begin{array}{l}\text { Model } 2 \\
\text { OR }(95 \% \mathrm{Cl})\end{array}$ \\
\hline \multicolumn{5}{|l|}{ Overall } \\
\hline Grade 1 & 11,691 & $531(4.5)$ & Reference & Reference \\
\hline Grade 2 & 5095 & $345(6.8)$ & $1.71(1.13-2.58)$ & $2.49(1.46-4.24)$ \\
\hline Grade 3 & 6797 & $468(6.9)$ & $1.83(1.21-2.76)$ & $3.61(2.13-6.14)$ \\
\hline Grade 4 or above & 4266 & $199(4.7)$ & $1.27(0.83-1.95)$ & $4.74(2.65-8.46)$ \\
\hline$p$-value & & & 0.003 & $<0.01$ \\
\hline \multicolumn{5}{|c|}{ No-mechanical ventilation } \\
\hline Grade 1 & 5081 & $69(1.4)$ & Reference & Reference \\
\hline Grade 2 & 2513 & $34(1.4)$ & $1.36(0.69-2.66)$ & $1.23(0.63-2.39)$ \\
\hline Grade 3 & 4877 & $59(1.2)$ & $1.68(0.90-3.14)$ & $1.51(0.80-2.86)$ \\
\hline Grade 4 or above & 3750 & $25(0.7)$ & $1.27(0.63-2.56)$ & $0.99(0.45-2.14)$ \\
\hline$p$-value & & & 0.395 & 0.359 \\
\hline \multicolumn{5}{|l|}{ Mechanical ventilation } \\
\hline Grade 1 & 6610 & $462(7.0)$ & Reference & Reference \\
\hline Grade 2 & 2582 & $311(12.0)$ & $2.00(1.24-3.24)$ & $2.73(1.51-4.95)$ \\
\hline Grade 3 & 1920 & $409(21.3)$ & $2.65(1.65-4.25)$ & $4.02(2.23-7.26)$ \\
\hline Grade 4 or above & 516 & $174(33.7)$ & $4.15(2.50-6.89)$ & $7.83(4.07-15.07)$ \\
\hline$p$-value & & & $<0.01$ & $<0.01$ \\
\hline
\end{tabular}

Model 1 adjusted for age, sex, and primary diagnosis

Model 2 further adjusted for medical/surgical admission, hospital type, interventions for critical care (vasopressor drugs, extracorporeal membrane oxygenation, and hemodialysis)

Cl confidence interval, $O R$ odds ratio, ICU intensive care unit 

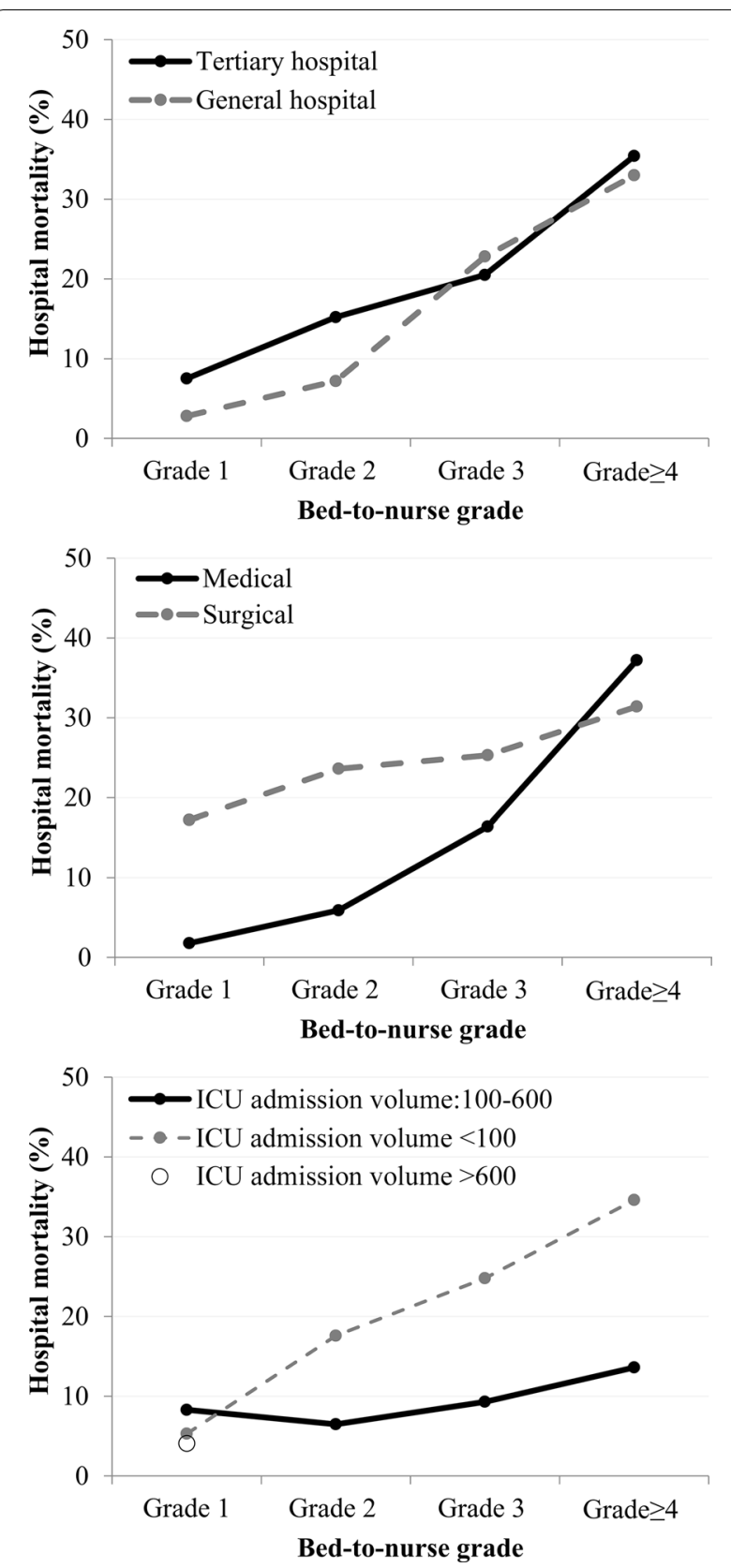

Fig. 2 Unadjusted hospital mortality of subgroups according to ICU bed-to-nurse grade in the mechanically ventilated patients

In our study, patients without mechanical ventilation did not show the association between nurse staffing ratio and adjusted mortality rate. According to a recent study, the difference in workload in mechanical ventilation might be a possible explanation for the absence of this association [33]. More importantly, the crude mortality of patients without mechanical ventilation was less than $1.5 \%$, whereas the crude death of ventilated patients ranged from 7.0 to $33.7 \%$ (Table 2). We think that the hospital mortality rate of patients without mechanical ventilation might be too low to detect the different consequences of low nurse staffing ratio. However, we cannot conclude that a high nurse staffing ratio is not effective in patients without mechanical ventilation since we do not know the effect of high nurse staffing ratio on outcomes (such as nosocomial infections, readmission rate, and patient satisfaction) other than mortality. We suspect that the different results among studies might be caused by the different proportions of mechanical ventilation or severity of patients in the study units. Severity of patients who use vasopressors likely requires more hemodynamic monitoring and labor, but there was no significant bedto-nurse effect on in-hospital mortality (Additional file 2: Table S1).

There are many studies about the volume-outcome relationship in critical care [34]. When we adjusted ICU admission volume for mortality, the effect of nurse staffing ratio was offset since the ICU admission volume was correlated with bed-to-nurse ratio (correlation coefficient: 0.714, $p<0.01$ ) (Additional file 3: Tables S2, S3). We think the volume-outcome relationship of ICU patients might be partly mediated by unmet standard qualities such as nurse staffing ratio, which might be driven from economies of scale. We could not know how much the nurse staffing ratio mediated the volume-outcome relationship. There could be other mediators of the volumeoutcome relationship, such as providers' experience, education, and technology capacity [34, 35]. However, we could not evaluate all possible partial mediators in this study.

There are some limitations to this study. Using claim data, which is primarily collected for administrative purposes, we could not account for physiologic or laboratory parameters. Although we adjusted patient severity by diagnosis, treatment requirements, and hospital admission factors, there were limitations in adjusting all casemix severity with the logistic regression model of this study. In addition, the study data were limited to that in the reimbursement system of Korean NHI for ICU staffing ratio. We could not obtain information on the clinical outcomes of a nurse staffing ratio of 1 ventilated patient per nurse compared to 2 ventilated patients per nurse. In this study, we focused on the quantity of nurse staffing; however, the quality of nurse staffing (education course, advanced training) and other ICU team members could be a confounder of mortality. Although we adjusted hospital types that share similar ICU organizational structures or educational programs, the statistical adjustment has limitations.

Despite these limitations, this nationwide scale study provided an overview of the effect of nurse staffing ratio without selection bias of hospital and patient, and 
highlighted the important effect of mechanical ventilation on the association of nurse staffing ratio and mortality rate.

Our findings also have clinical implications. Even though we know high workload is associated with the poor clinical outcome [33], we could not know the individual patient's workload before we measure it. However, we could assume the ventilated patients require a high nurse staffing ratio at the time of assigning duty, and nurse allocation should prioritize patients on mechanical ventilation even compared to those using only vasopressors (Additional file 2: Table S1). In addition, our findings have implications related to policymaking. California law limits an ICU nurse to care for a maximum of 2 patients, regardless of the patients' ventilation state [36]. When a shortage of nurses becomes a concern, it could be considered to refine the regulation to apply to patients on mechanical ventilation.

\section{Conclusion}

As the bed-to-nurse ratio of an ICU increased, the adjusted mortality rate in mechanically ventilated patients increased significantly. Although further studies on ICU volume effects are required, there should be consideration of a policy that limits the number of ventilated patients to 2 or less per nurse in an ICU.

\section{Supplementary Information}

The online version contains supplementary material available at https://doi. org/10.1186/s13613-020-00780-7.

Additional file 1: Figure S1. Flowchart of patient selection with inclusion and exclusion.

Additional file 2: Table S1. Odds ratio $(95 \% \mathrm{Cl})$ for in-hospital mortality according to ICU grade and combination of mechanical ventilator and vasopressor drugs, 2009 to 2014

Additional file 3: Table S2. Pearson correlation coefficients among hospital variables. Odds ratio for in-hospital Mortality of patients with mechanical ventilation in volume-stratified subgroups.

\section{Abbreviations}

ICU: Intensive care unit; HIRA: Health Insurance Review and Assessment; NHI: National Health Insurance; ATC: Anatomic therapeutic chemical; Cl: Confidence interval.

\section{Acknowledgements}

Not applicable.

\section{Authors' contributions}

MJ, HP, JC conceived the study idea. MJ, EP, HP, JC, GYS, KJ, CRC, JHY, JC2, and EG designed the study. JC2, HP, DK were responsible for collecting data. JC2, $H P, D K$ and EG provided statistical expertise. MJ, EP, and HP wrote the first draft of the manuscript. EG, JC2 , and JC made critical revisions of the manuscript content. All the authors contributed to the interpretation of the results. All authors read and approved the final manuscript.

\section{Funding}

No external funding was provided.

\section{Availability of data and materials}

The researchers can access on the intranet of Korean Health Insurance Review \& Assessment Service through the URL: http://opendata.hira.or.kr/home.do after approval of the request. The researchers can request the same periods, terms and items (claim code) as done in this study. The authors did not have any special access privileges that others would not have.

\section{Ethics approval and consent to participate}

Our study was reviewed by the Institutional Review Board of Samsung Medical Center, and informed consent was exempted because of the use of previously collected de-identified data.

\section{Consent for publication}

Not applicable.

\section{Competing interests}

The authors declare that they have no competing interests.

\section{Author details}

${ }^{1}$ Department of Pediatrics, Kosin University Gospel Hospital, Kosin University School of Medicine, Busan, Republic of Korea. ${ }^{2}$ Department of Critical Care Medicine, Samsung Medical Center, Sungkyunkwan University School of Medicine, 81 Irwon-ro, Gangnam-gu, Seoul 06351, Republic of Korea. ${ }^{3}$ Center for Clinical Epidemiology, Samsung Medical Center, Seoul, Republic of Korea. ${ }^{4}$ Department of Clinical Research Design \& Evaluation, SAIHST, Sungkyunkwan University, Seoul, South Korea. ${ }^{5}$ Departments of Epidemiology and Department of Medicine, Welch Center for Prevention, Epidemiology, and Clinical Research, Johns Hopkins Bloomberg School of Public Health, Baltimore, MD, USA

Received: 31 May 2020 Accepted: 21 November 2020

Published online: 30 November 2020

References

1. Needleman J, Buerhaus P, Mattke S, Stewart M, Zelevinsky K. Nursestaffing levels and the quality of care in hospitals. N Engl J Med. 2002;346(22):1715-22.

2. Cho SH, Ketefian S, Barkauskas VH, Smith DG. The effects of nurse staffing on adverse events, morbidity, mortality, and medical costs. Nurs Res. 2003;52(2):71-9.

3. Needleman J, Buerhaus P, Pankratz VS, Leibson CL, Stevens SR, Harris M. Nurse staffing and inpatient hospital mortality. N Engl J Med. 2011;364(11):1037-45.

4. Aiken LH, Sloane DM, Bruyneel L, Van den Heede K, Griffiths P, Busse $R$, et al. Nurse staffing and education and hospital mortality in nine European countries: a retrospective observational study. Lancet. 2014;383(9931):1824-30.

5. Marcin JP, Rutan E, Rapetti PM, Brown JP, Rahnamayi R, Pretzlaff RK. Nurse staffing and unplanned extubation in the pediatric intensive care unit. Pediatr Crit Care Med. 2005;6(3):254-7.

6. Stone PW, Mooney-Kane C, Larson EL, Horan T, Glance LG, Zwanziger J, et al. Nurse working conditions and patient safety outcomes. Med Care. 2007;45(6):571-8.

7. Dancer SJ, Coyne M, Speekenbrink A, Samavedam S, Kennedy J, Wallace PG. MRSA acquisition in an intensive care unit. Am J Infect Control. 2006;34(1):10-7.

8. Chamberlain D, PollockW, Fulbrook P. Group AWSD ACCCN workforce standards for intensive care nursing: systematic and evidence review, development, and appraisal. Aust Crit Care. 2018;31(5):292-302.

9. Bray K, Wren I, Baldwin A, St Ledger U, Gibson V, Goodman S, et al. Standards for nurse staffing in critical care units determined by: The British Association of Critical Care Nurses, The Critical Care Networks National Nurse Leads, Royal College of Nursing Critical Care and In-flight Forum. Nurs Crit Care. 2010;15(3):109-11.

10. Reis Miranda D, Moreno R, lapichino G. Nine equivalents of nursing manpower use score (NEMS). Intensive Care Med. 1997;23(7):760-5.

11. Cullen DJ, Civetta JM, Briggs BA, Ferrara LC. Therapeutic intervention scoring system: a method for quantitative comparison of patient care. Crit Care Med. 1974;2(2):57-60. 
12. Neuraz A, Guerin C, Payet C, Polazzi S, Aubrun F, Dailler F, et al. Patient mortality is associated with staff resources and workload in the ICU: a multicenter observational study. Crit Care Med. 2015;43(8):1587-94.

13. Kane RL, Shamliyan TA, Mueller C, Duval S, Wilt TJ. The association of registered nurse staffing levels and patient outcomes: systematic review and meta-analysis. Med Care. 2007;45(12):1195-204.

14. Watson R. The global shortage of registered nurses. J Clin Nurs. 2005;14(4):409.

15. Kelly DM, Kutney-Lee A, McHugh MD, Sloane DM, Aiken LH. Impact of critical care nursing on 30-day mortality of mechanically ventilated older adults. Crit Care Med. 2014;42(5):1089-95.

16. Numata Y, Schulzer M, van der Wal R, Globerman J, Semeniuk P, Balka E, et al. Nurse staffing levels and hospital mortality in critical care settings: literature review and meta-analysis. J Adv Nurs. 2006;55(4):435-48.

17. Penoyer DA. Nurse staffing and patient outcomes in critical care: a concise review. Crit Care Med. 2010;38(7):1521-8 (quiz 9).

18. Kim JA, Yoon S, Kim LY, Kim DS. Towards actualizing the value potential of Korea Health Insurance Review and Assessment (HIRA) data as a resource for health research: strengths, limitations, applications, and strategies for optimal use of HIRA data. J Korean Med Sci. 2017;32(5):718-28.

19. Jung M, Park H, Kang D, Park J, Jeon K, Chung CR, et al. Age-specific distribution of diagnosis and outcomes of children admitted to ICUs: a population-based cohort study. Pediatr Crit Care Med. 2019;20(7):e301-10.

20. Cho SH, Hwang JH, Kim J. Nurse staffing and patient mortality in intensive care units. Nurs Res. 2008;57(5):322-30.

21. Lankshear AJ, Sheldon TA, Maynard A. Nurse staffing and healthcare outcomes: a systematic review of the international research evidence. ANS Adv Nurs Sci. 2005;28(2):163-74.

22. Lee YS, Lee YR, Chae Y, Park SY, Oh IH, Jang BH. Translation of Korean medicine use to ICD-codes using national health insurance servicenational sample cohort. Evid Based Complement Alternat Med. 2016;2016:8160838.

23. Weisz D, Gusmano MK, Rodwin VG. Gender and the treatment of heart disease in older persons in the United States, France, and England: a comparative, population-based view of a clinical phenomenon. Gend Med. 2004;1(1):29-40

24. Miranda DR, Nap R, de Rijk A, Schaufeli W, lapichino G. System TWGTIS nursing activities score. Crit Care Med. 2003;31(2):374-82.

25. Miranda DR, de Rijk A, Schaufeli W. Simplified therapeutic intervention scoring system: the TISS-28 items — results from a multicenter study. Crit Care Med. 1996;24(1):64-73.
26. Tarnow-Mordi WO, Hau C, Warden A, Shearer AJ. Hospital mortality in relation to staff workload: a 4-year study in an adult intensive-care unit. Lancet. 2000;356(9225):185-9.

27. Carayon P, Gurses AP. A human factors engineering conceptual framework of nursing workload and patient safety in intensive care units. Intensive Crit Care Nurs. 2005;21(5):284-301.

28. Llenore E, Ogle KR. Nurse-patient communication in the intensive care unit: a review of the literature. Aust Crit Care. 1999;12(4):142-5.

29. Baggs JG, Schmitt MH, Mushlin Al, Mitchell PH, Eldredge DH, Oakes D, et al. Association between nurse-physician collaboration and patient outcomes in three intensive care units. Crit Care Med. 1999;27(9):1991-8.

30. Hsu CW, Sun SF. latrogenic pneumothorax related to mechanical ventilation. World J Crit Care Med. 2014;3(1):8-14.

31. Beckmann U, Baldwin I, Durie M, Morrison A, Shaw L. Problems associated with nursing staff shortage: an analysis of the first 3600 incident reports submitted to the Australian Incident Monitoring Study (AIMS-ICU). Anaesth Intensive Care. 1998;26(4):396-400.

32. Ream RS, Mackey K, Leet T, Green MC, Andreone TL, Loftis LL, et al. Association of nursing workload and unplanned extubations in a pediatric intensive care unit. Pediatr Crit Care Med. 2007;8(4):366-71.

33. Margadant C, Wortel S, Hoogendoorn M, Bosman R, Spijkstra JJ, Brinkman $\mathrm{S}$, et al. The nursing activities score per nurse ratio is associated with in-hospital mortality, whereas the patients per nurse ratio is not. Crit Care Med. 2020;48(1):3-9.

34. Nguyen YL, Wallace DJ, Yordanov Y, Trinquart L, Blomkvist J, Angus DC, et al. The volume-outcome relationship in critical care: a systematic review and meta-analysis. Chest. 2015;148(1):79-92.

35. Kahn JM. Volume, outcome, and the organization of intensive care. Crit Care. 2007;11(3):129.

36. Aiken LH, Sloane DM, Cimiotti JP, Clarke SP, Flynn L, Seago JA, et al. Implications of the California nurse staffing mandate for other states. Health Serv Res. 2010;45(4):904-21.

\section{Publisher's Note}

Springer Nature remains neutral with regard to jurisdictional claims in published maps and institutional affiliations.

\section{Submit your manuscript to a SpringerOpen ${ }^{\circ}$ journal and benefit from:}

- Convenient online submission

- Rigorous peer review

- Open access: articles freely available online

- High visibility within the field

- Retaining the copyright to your article

Submit your next manuscript at springeropen.com 